\title{
Case Report: A Pediatric COVID-19 Patient with Pyelonephritis and Febrile Seizure as a Rare Clinical Manifestations
}

\author{
Masoud Rezagholizamenjany (iD ${ }^{1,}$, , Parsa Yousefichaijan (iD ${ }^{2}$, Fakhreddin Shariatmadari ${ }^{1}$, Manijeh \\ Kahbazi ${ }^{3}$, Vahid Falahati ${ }^{4}$, Yazdan Gandi ${ }^{5}$ and Javad Nazari ${ }^{6}$ \\ ${ }^{1}$ School of Medicine, Arak University of Medical Sciences, Arak, Iran \\ ${ }^{2}$ Amir Kabir Hospital, Department of Pediatric Nephrology, Arak University of Medical Sciences, Arak, Iran \\ ${ }^{3}$ Amir Kabir Hospital, Department of Pediatric, Arak University of Medical Sciences, Arak, Iran \\ ${ }^{4}$ Amir Kabir Hospital, Department of Pediatric Hematology, Arak University of Medical Sciences, Arak, Iran \\ ${ }^{5}$ Amir Kabir Hospital, Department of Pediatric Cardiology, Arak University of Medical Sciences, Arak, Iran \\ ${ }^{6}$ Department of Pediatric, Arak University of Medical Sciences, Arak, Iran \\ "Corresponding author: School of Medicine, Arak University of Medical Sciences, Arak, Iran. Email: masoudrezagholi074@gmail.com
}

Received 2021 May 19; Accepted 2021 June 13.

\begin{abstract}
In this study, we report a rare presentation of COVID-19 virus, as febrile seizure. The patient was a 13-month-old girl with febrile seizure. Fever of the patient had started three days ago. Also, the patient had chills for five minutes in addition to cyanosis and tachycardia. On the primary evaluation, active urine analysis showed pyelonephritis. After a complete evaluation, the patient was diagnosed as a positive COVID-19 case based on polymerase chain reaction using nasopharyngeal and oropharyngeal swabs.
\end{abstract}

Keywords: Child, SARS-CoV-2, Febrile Seizure, Pyelonephritis

\section{Introduction}

Human coronaviruses (HCoVs), which have been known since the late 1960s, are able to introduce infection in both animals and humans. This type of virus induces enteric, neurologic, hepatic, and respiratory diseases in different animals, which, in some cases may be severe (1, 2).

In humans, it takes five to six days for symptoms to present, but it may extend to 14 days. Until the pathogen known as the etiology of severe acute respiratory syndrome (SARS) was isolated, that was already known as HCoVs, it was assumed that it does not have a clinical role in children (3). However, in recent studies on SARS-CoV2 , the available data also exhibits that this infection can cause mild upper respiratory tract infections (URTIs) in pediatrics (4), and those with an underlying condition it may induce severe lower respiratory tract infections (LRTIs) (5, 6). However, studies have not addressed the possible relationship between the disease and extra-respiratory involvements, including the central nervous system (CNS), in which SARS-CoV-2 may induce chronic neurologic disorders $(7,8)$. Since the identification of SARS-CoV and 2 novel
HCoVs isolation in humans (SARS-CoV-2), numerous studies have been conducted on the epidemiology, and socioeconomic and clinical effects this type of infection $(9,10)$, but rare clinical manifestations of this disease have been evaluated in limited studies. In this case, we describe a case with febrile seizure as a rare neurologic sign of COVID-19.

\section{Case Presentation}

We report a rare presentation of COVID-19 as febrile seizure. The patient was a 13-month-old girl with complete vaccinations and without history of close contact with a patient with respiratory signs and symptoms. The patient had febrile seizure, and the fever had started three days ago. The patient had a recent chills for five minutes, she also had cyanosis and tachycardia. The patient was admitted for further evaluations.

Because of cyanosis, ECG was performed, which showed normal signs. However, laboratory findings showed an inflammatory condition (Table 1), and U/A showed an active condition. Based on related clinical manifestations, she was diagnosed to have pyelonephritis (Table 2). High-resolution computed tomography (HRCT) 
of chest revealed a peripheral and hilar ground glass involvement, but there was a normal chest X-ray (Figure 1). In addition, based on paraclinical findings, we further evaluated the patient for SARS-Cov-2 infection. Following a complete evaluation, the patient was diagnosed as a positive COVID-19 case, based on polymerase chain reaction (PCR), using nasopharyngeal and oropharyngeal swabs, and chest HRCT. Thus, the patient was treated, and after five days of admission, she was discharged with normal vital signs.

\begin{tabular}{lc}
\hline Table 1. Laboratory Findings of the Patient Affected by & SARS-CoV-2 \\
\hline Variables & Findings \\
\hline CRP & $3+$ \\
WBC & $12.83 \times 10^{3} / \mu \mathrm{L}$ \\
\hline Neutrophil & $65 \%$ \\
\hline Lymphocyte & $28 \%$ \\
\hline Plt & $358 \times 10^{3} / \mu \mathrm{L}$ \\
\hline ESR & $106 \mathrm{~mm} / \mathrm{h}$ \\
\hline Hgb & $10.5 \mathrm{gr} / \mathrm{dL}$ \\
\hline Urea & 21 \\
\hline Cr & 0.80 \\
\hline Na & 137 \\
\hline K & 4.4 \\
Trop & Negative \\
Blood Culture & Negative \\
\hline
\end{tabular}

Table 2. Urine Analysis Results of the Patient Affected by SARS-CoV-2

\begin{tabular}{lc}
\hline Variables & Findings \\
\hline Color & Yellow \\
Appearance & Semi Turbid \\
\hline Urine Specify Gravity & 1.020 \\
PH & 6 \\
\hline W.B.C & Many \\
R.B.C & $0-1$ \\
\hline EP & $0-1$ \\
\hline Bacteria & Few \\
\hline
\end{tabular}

\section{Discussion}

In this study, a pediatric COVID-19 patient with febrile seizure as a rare clinical manifestation was described. In some other studies, extra respiratory problems, including central nervous system (CNS) involvement, have been mentioned, but rarely febrile seizure has been described as the first clinical manifestation. The relationship of HCoV infection with acute neural disorders was found by $\mathrm{HCoV}$ OC43 detection in the cerebrospinal fluid of a child with acute encephalomyelitis; disseminated and frequent relationships of febrile seizures development and HCoV-HKU1 infection lead to the same conclusion. Woo et al. evaluated 10 pediatric patients with COVID-19 and observed that $50 \%$ of the cases had febrile seizure (11). Since fever in these cases was not high and lasted for a lower period than fever associated with other respiratory infections, it was considered unlikely that they were simple febrile seizures, but they may represent neurologic conditions caused by HCoVHKU1 or that the virus may induce an immune response.

In a study by Lau et al. among 629 children with reproductive tract infections (RTIs), inpatients 11 cases were diagnosed with upper respiratory tract infections (URTIs), five cases with febrile seizures, one case with bronchiolitis, and one case with pneumonia, that is, $0.7 \%$ of the cases presented with febrile seizure (12). In addition, in another study by Vabret et al., among 83 cases with RTIs aged $<5$, three patients showed gastroenteritis, and one had febrile seizures (13). However, in limited studies febrile seizure has been reported as a clinical manifestation of SARS-CoV-2 infection.

\subsection{Conclusion}

Some presentations of COVID-19 are rare and may go undiagnosed. Febrile seizure as a rare clinical manifestation may be missed; thus, considering this presentation as a clinical manifestation of SARS-CoV-2 can be effective in patient diagnosis.

\section{Footnotes}

Authors' Contribution: All authors contributed equally in manuscript preparation and submission.

Conflict of Interests: None declared.

Ethical Approval: This study was approved by the Ethics Committee of Arak University of Medical Sciences with the code of ethics IR.ARAKMU.REC.1399.156.

Funding/Support: Our study was funded by Arak University of Medical Sciences.

Informed Consent: We obtained informed consent from our case. 


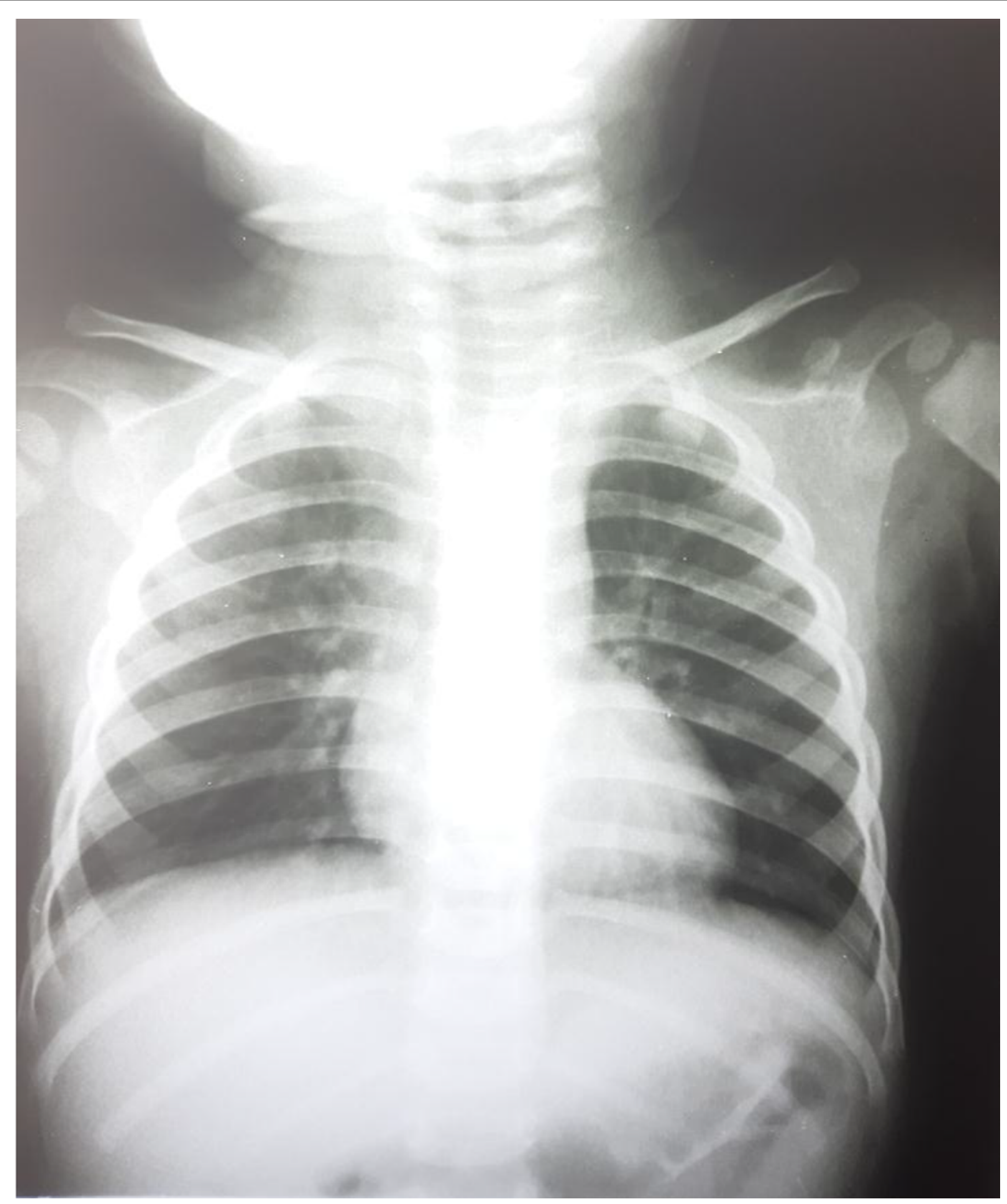

Figure 1. Chest X-ray of the patient affected by SARS-CoV-2 


\section{References}

1. Liu Y, Chen H, Tang K, Guo Y. Withdrawn: Clinical manifestations and outcome of SARS-CoV-2 infection during pregnancy.J Infect. 2020. doi: 10.1016/j.jinf.2020.02.028. [PubMed: 32145216]. [PubMed Central: PMC7133645].

2. Principi N, Bosis S, Esposito S. Effects of coronavirus infections in children. Emerg Infect Dis. 2010;16(2):183-8. doi: 10.3201/eid1602.090469. [PubMed: 20113545]. [PubMed Central: PMC2957994].

3. Lai CC, Shih TP, Ko W, Tang HJ, Hsueh PR. Severe acute respiratory syndrome coronavirus 2 (SARS-CoV-2) and coronavirus disease-2019 (COVID-19): The epidemic and the challenges. Int J Antimicrob Ag. 2020;55(3):105924. doi: 10.1016/j.ijantimicag.2020.105924.

4. Rahimzadeh G, Ekrami Noghabi M, Kadkhodaei Elyaderani F, Navaeifar MR, Enayati AA, Manafi Anari A, et al. COVID-19 Infection in Iranian Children: A Case Series of 9 Patients.JPediatr Rev. 2020;8(1(18)):139-44. doi: 10.32598/jpr.8.2.139.

5. Zou L, Ruan F, Huang M, Liang L, Huang H, Hong Z, et al. SARS-CoV2 viral load in upper respiratory specimens of infected patients. $N$ Engl J Med. 2020;382(12):1177-9. doi: 10.1056/NEJMc2001737. [PubMed: 32074444]. [PubMed Central: PMC7121626].

6. Perico L, Benigni A, Remuzzi G. Should COVID-19 concern nephrologists? Why and to what extent? The emerging impasse of angiotensin blockade. Nephron. 2020;144(5):213-21. doi: 10.1159/000507305. [PubMed: 32203970]. [PubMed Central: PMC7179544].

7. Young BE, Ong SWX, Kalimuddin S, Low JG, Tan SY, Loh J, et al. Epidemiologic features and clinical course of patients infected with SARS-CoV-2 in Singapore. JAMA. 2020;323(15):1488-94. doi: 10.1001/jama.2020.3204. [PubMed: 32125362]. [PubMed Central: PMC7054855].

8. Xu XW, Wu XX, Jiang XG, Xu KJ, Ying LJ, Ma CL, et al. Clinical findings in a group of patients infected with the 2019 novel coronavirus (SARS-Cov-2) outside of Wuhan, China: Retrospective case series. BMJ. 2020;368:m606. doi: 10.1136/bmj.m606. [PubMed: 32075786]. [PubMed Central: PMC7224340].

9. Yang X, Yu Y, Xu J, Shu H, Xia J, Liu H, et al. Clinical course and outcomes of critically ill patients with SARS-CoV-2 pneumonia in Wuhan, China: A single-centered, retrospective, observational study. Lancet Respir Med. 2020;8(5):475-81. doi: 10.1016/S2213-2600(20)30079-5. [PubMed 32105632]. [PubMed Central: PMC7102538].

10. Zhang JJ, Dong X, Cao YY, Yuan YD, Yang YB, Yan YQ, et al. Clinical characteristics of 140 patients infected with SARS-CoV-2 in Wuhan, China. Allergy. 2020;75(7):1730-41. doi: 10.1111/all.14238. [PubMed: 32077115].

11. Woo PC, Lau SK, Chu CM, Chan KH, Tsoi HW, Huang Y, et al. Characterization and complete genome sequence of a novel coronavirus, coronavirus HKU1, from patients with pneumonia. JVirol. 2005;79(2):88495. doi: 10.1128/JVI.79.2.884-895.2005. [PubMed: 15613317]. [PubMed Central: PMC538593].

12. Lau SK, Woo PC, Yip CC, Tse H, Tsoi HW, Cheng VC, et al. Coronavirus HKU1 and other coronavirus infections in Hong Kong.J Clin Microbiol. 2006;44(6):2063-71. doi: 10.1128/JCM.02614-05. [PubMed: 16757599]. [PubMed Central: PMC1489438].

13. Vabret A, Dina J, Gouarin S, Petitjean J, Corbet S, Freymuth F. Detection of the new human coronavirus HKU1: A report of 6 cases. Clin InfectDis. 2006;42(5):634-9. doi: 10.1086/500136. [PubMed: 16447108]. [PubMed Central: PMC7107802] 